\title{
Quality of life in psoriasis patients
}

\author{
*Fatma M Abd Al Salam.,** Seham F Mohamed, **Taghreed M El-Shafie. \\ ** Hesham M Abuhegazy \\ * Department of Dermatology and Venereology., \\ ** Department of psychiatry Al Azhar University
}

\begin{abstract}
Skin and psyche share embryonic origins, various psychological factors, including emotional trauma and stressful life events, may affect both onset and progression of some skin conditions, Psoriasis is a chronic skin disease with substantial impact on patient's social and relational ways of living and subsequently on their quality of life. This chronic condition has a significant negative impact on patients' quality of life. Psoriasis has been linked to patients depression and suicidal tendencies Patients and Methods The study group consisted of 50 consenting consecutive cases of psoriasis vulgaris, of both sexes, aged 18-62 years (41.44 \pm 0.101 ), and with duration of the disease 6-10 years, attending the dermatology outpatient clinic of Al Zahraa university hospital. The extent of clinical severity of the disease was assessed by the psoriatic area and severity index (PASI Score), Assessment of quality of life of patients by Lehman Quality of Life Interview (LQLI) .According toPASI score they were devided into 3 groups :mild cases were treated by topical steroid and salyslic acid while moderate cases were treated by NB-UVB and severe cases were treated by systemic methotrexate. Results showed that $57.4 \%$ of patients were unsatisfied with their family relations and $43.5 \%$ are satisfied. However, about their social relations they were $55.3 \%$ satisfied while $44.6 \%$ were unsatisfied. In the other hand, they were $52.3 \%$ satisfied with their finance while the other $48.2 \%$ were unsatisfied with it. As regard, work or school they were $66.4 \%$ satisfied and $33.5 \%$ unsatisfied. While they were $85.1 \%$ satisfied with low, safety, and $14.8 \%$ unsatisfied. The same for health 94.4\% satisfied and $6.5 \%$ unsatisfied .The third group treated by systemic methotrexate show marked increase in LQLI. Conclusions: Psoriasis is a disease with profound impact on the psychological and social aspect of the patient, particularly because of its visibility. Systemic therapy of psoriasis could improve their quality of life. Thus assessment by a health professional of the extent of apparent disease in terms of the clinical severity alone may not suffice, and a more holistic approach to the quality of life is mandatory.
\end{abstract}

Key Words: Psoriasis, Quality of life

\section{Introduction:}

Skin plays a vital role in the maintenance of physical and mental health. Skin retains the ability to respond to both endogenous and exogenous stimuli, sensing and integrating environmental cues while transmitting intrinsic conditions to the outside world. As such, it has long been a target for the application of both medical and non medical therapies of healthy and diseased states (Wahl et al., 2002). Psoriasis is a chronic skin disease with substantial impact on patients social and relational ways of living and subsequently on their quality of life. This chronic condition has a significant negative impact on patients' quality of life. Psoriasis has been linked to the depression and suicidal tendencies. (Prins et al., 2005)

Psoriasis has a significant negative impact on patients' health related quality of life (HRQoL). In a survey by the National Psoriasis Foundation almost $75 \%$ of patients believed that psoriasis had moderate to large negative impact on their quality of life (QoL), with alterations in their daily activities(Fortune et al., 2005) Furthermore, physical and emotional effects of psoriasis were found to have a significant 
negative impact at patients' workplace. (De Arruda and De Moraies., 2001)

Absenteeism is a greater concern for people suffering from psoriasis than their co-workers without psoriasis with nearly $60 \%$ patients reporting missing an average of 26 days a year directly related to their psoriasis. (Feldman et al., 1997)

Patients with psoriasis have a higher financial burden due to absenteeism in addition to the cost of caring for their disease (Finlay and Colles, 1995)

Psoriasis patients often experience difficulties like maladaptive coping responses, problems in body image, self esteem, self concept and also have feelings of stigma, shame and embarrassment regarding their appearance. (Rapp et al., 1999).

Individuals with psoriasis commonly engage in coping strategies to avoid unwanted and unpleasant social consequences. However, most of these strategies fail to improve patients' QoL (Feldman et al., 1997and Finlay and Colles, 1995)

So the current study aimed to assese the quality of life in psoriatic patients.

\section{Material and Methods:}

The present study include 50 consenting consecutive patients of psoriasis vulgaris, of both sexes. They were 29 males and 21 females, their age ranging from 1862 years and the duration of disease between 6-10 years. They were selected from the dermatology outpatient clinic of Al Zahraa university hospital. The extent of clinical severity of the disease was assessed by the psoriasis area and severity index (PASI) Score. Assessment of quality of life of patients by Lehman Quality of Life Interview (LQLI). Social classification of the subjects is conducted according to an Egyptian classification of (Fahmy and ElSherbin, 1988)

Psoriasis area and severity Index (PASI

Score) (Weiss et al., 2002)

Four main areas were assessed for calculation of PASI Score:- The head, the trunk, the upper extremities and the lower extremities corresponding to 10\%-20\%$30 \%$ - and $40 \%$ of the total body area respectively. The lesion are given a score for redness, thickness and scaling, a formula is then applied to give the score . The maximum score for PASI is 72 .

Lehman Quality of Life Interview

(LQLI) (Traver et al., 1998 and Sajatovicand and Ramirez, 2003)

This is scale, by Lehman, initially developed in 1983. The QOLI is a widelyused and well-validated scale.The QOLI is a structured self-report interview.domains measured include general living situation, daily activities and functioning, family and social relationships, finances, work and school, legal and safety issues, and health. The patient on average takes 10-20 minutes to complete the instrument. The scale used in this research is the short version (TL$30 \mathrm{~S})$. It is a 33 item instrument derived from the QOLI, and it takes about 10 minutes to complete. Each of the items in the subjective dimension is measured on a 1- to 7-point "feeling" scale, where 1 indicates "terrible" and 7 indicates "delighted." Where at least 60 percent of the scale's items are completed, a mean value is calculated for each domain (general, housing, etc.).

\section{Results}

Fifty patients (29 males, 21 females) were included in the study. Among the physical and psychosocial factors investigated, daily activities, employment, and treatment were reported to be affected the most. Psoriasis sufferers are also most likely to feel self-conscious, be disturbed / inconvenienced by the shedding of the skin, live in a constant fear of relapse, and avoid social interactions.

\section{Group Characteristics:}

The age criterion for patients group above 18 years. (Fig.1)The mean age was 41.44 years \pm 0.101 for patients. The marital status were single in $(71.89 \%)$, married $(16.94 \%)$, divorced in $(9.67 \%)$ and widow in $(1.39 \%)$. 

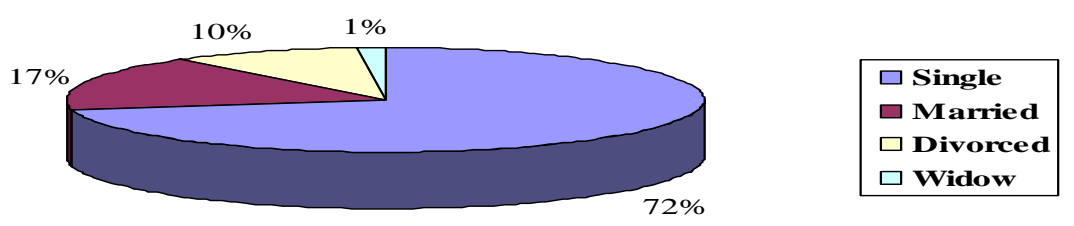

Fig (1): Marital status in patients

The Social classification is based on the following parameters

1 Education of the father

2 Education and work of the mother

3 Income

4 Crowding index

5 Sanitation.

Table (1): Social classification of patients.

\begin{tabular}{|l|l|l|l|l|}
\hline \multicolumn{2}{|c|}{} & \% & $\square^{2}$ & $\boldsymbol{P}$ \\
\hline \multirow{3}{*}{} & High & 1.9 & 2.789 & 0.054 \\
\cline { 2 - 5 } Med & 7.43 & 2.378 & 0.059 \\
\cline { 2 - 5 } & Low & 30.9 & 2.15 & 0.061 \\
\cline { 2 - 5 } & Very low & 30.57 & 3.875 & $0.043^{*}$ \\
\hline
\end{tabular}

Significant at $\mathrm{P} \leq 0.05$ using Chi square test

According to PASI Score the psoriasis patient are divided into 3 groups.

The first group includes 28 patients of mild psoriasis (15 male and 13 female) with PASI Score (5.6-10.9). The second group includes 13 patients of moderate psoriasis (9male and 4 female) with PASI Score (12.2-19.6). The third group include 9 patients with severe psoriasis vulgaris (5male and 4 female) with PASI Score (21.2-29.6). The three groups receveid treatment for 12 weeks as follow:

- The frist group was treated by topical corticosteroid(Betamethasone valerate) twice daily and topical salyslic acid ointment $3 \%$ at bed time.

- The second group was treated by Narrow band Ultraviolet $\mathrm{B}$ radiation (NBUVB) patients are evaluated to determine the maximum amount of light they can tolerate without developing erythema or reddening of skin [minimal erythema dose (MED)]. The treatment begins by $50 \%$ MED and the exposure gradually increase $40 \mathrm{mj} / \mathrm{sec}$ every other day.

- The third group was treated by systemic methotrexate $15 \mathrm{mg} /$ week.

Table (2 ): Represent PASI Score of patients before and after treatment.

\begin{tabular}{|l|l|l|}
\hline & Before treatment & After treatment \\
\hline First group & $5.6-10.9$ & $4.1-7.6$ \\
\hline Second group & $12.2-19.6$ & $6.9-9.2$ \\
\hline Third group & $21.2-29.6$ & $14.2-27.1$ \\
\hline
\end{tabular}

This table showed that patient PASI Score improved with treatment specially the second group.

Leman quality of life interview was repeated after treatment. 


\section{Quality of Life in Psoriasis Patients:}

Patients in this study assessed regarding their quality of life by Lehman Quality of Life interview which assess Domains include general living situation(GLS), daily activities and functioning, family and social relationships, finances, work and school, legal and safety issues, and health just before start of treatment. The results are presented in Table 3.

The results showed that psoriasis patients included in this study reported that 59.5\% of the total sample are unsatisfied with their global functioning, while $44.4 \%$ are satisfied.

As regard living situations, we found that
$50.2 \%$ were unsatisfied, while $49.7 \%$ were satisfied. While their answers about daily work and activities were satisfied in $65.9 \%$ and unsatisfied for $34.1 \%$.

Results showed that $57.4 \%$ of patients were unsatisfied with their family relations and $43.5 \%$ are satisfied. However, about their

Social relations they were $55.3 \%$ satisfied while $44.6 \%$ were unsatisfied with it. In the other hand, they were $52.3 \%$ satisfied with their finance while the other $48.2 \%$ were unsatisfied with it.

As regard, work or school they were $66.4 \%$ satisfied and $33.5 \%$ unsatisfied. While they were $85.1 \%$ satisfied with low, safety, and $14.8 \%$ unsatisfied. The same for health $94.4 \%$ satisfied and $6.5 \%$ unsatisfied.

Table(3) : Quality of Life in Psoriases Patients before treatment

\begin{tabular}{|l|l|l|l|l|l|l|l|l|}
\hline Q LI & GLS & $\begin{array}{l}\text { Daily } \\
\text { activity }\end{array}$ & Family & Social R & Finance & Work & Legal & Health \\
\hline Satisfied & $49.70 \%$ & $65.90 \%$ & $43.50 \%$ & $55.30 \%$ & $52.30 \%$ & $66.40 \%$ & $85.10 \%$ & $94.40 \%$ \\
\hline $\begin{array}{l}\text { Unsatisfie } \\
\text { d }\end{array}$ & $50.20 \%$ & $34.10 \%$ & $57.40 \%$ & $44.60 \%$ & $48.20 \%$ & $33.50 \%$ & $14.80 \%$ & $6.50 \%$ \\
\hline
\end{tabular}

Table (4): The study applied to both affected male and female assessing their quality of life.

\begin{tabular}{|l|l|l|l|l|l|l|l|l|}
\hline $\begin{array}{l}\text { Q LI of } \\
\text { male }\end{array}$ & GLS & $\begin{array}{l}\text { Daily } \\
\text { activity }\end{array}$ & Family & Social R & Finance & Work & Legal & Health \\
\hline Satisfied & $53.5 \%$ & $69.3 \%$ & $36.20 \%$ & $65.5 \%$ & $24.9 \%$ & $19.7 \%$ & $85.10 \%$ & $94.40 \%$ \\
\hline $\begin{array}{l}\text { Unsatisfie } \\
\text { d }\end{array}$ & $46.1 \%$ & $36.7 \%$ & $58.2 \%$ & $39.50 \%$ & $78.6 \%$ & $83.3 \%$ & $14.80 \%$ & $6.50 \%$ \\
\hline $\begin{array}{l}\text { Q LI of } \\
\text { female }\end{array}$ & GLS & $\begin{array}{l}\text { Daily } \\
\text { activity }\end{array}$ & Family & Social R & Finance & Work & Legal & Health \\
\hline Satisfied & $50.63 \%$ & $39.90 \%$ & $45.70 \%$ & $49.30 \%$ & $39.90 \%$ & $80.30 \%$ & $83.70 \%$ & $83.50 \%$ \\
\hline $\begin{array}{l}\text { Unsatisfie } \\
\text { d }\end{array}$ & $68.7 \%$ & $57.10 \%$ & $54.40 \%$ & $51.60 \%$ & $62.20 \%$ & $19.0 \%$ & $15.40 \%$ & $18.90 \%$ \\
\hline
\end{tabular}

This table showed that most of male patient satisfied their general living situation, daily activities and social relationships, while most of them showed unsatisfiction with their finances, work and school and family relations.

Female results showed marked difference as regard their quality of life most of them are satisfied with their general living situation and work, but they are unsatisfied with daily activities, social relationships finances, work and school and family relations.

Both groups male and female showed satisfaction with services they received like legal and health. 
Lehman quality of life interview which repeated after treatment showed marked change in results of third group those received systemic methotraxate $15 \mathrm{mg} \mid$ week as they show marked improvement as regard their GLS, daily activity, social and family relations. While patients in both groups first and second show no change than their pretreatment results.

Table (5): Shows results of satisfaction among third group before and after treatment.

\begin{tabular}{|l|l|l|l|l|}
\hline LQL & GLS & Daily activity & family & Social relation \\
\hline Before treatment & $45.6 \%$ & $59 \%$ & $35.6 \%$ & $56.6 \%$ \\
\hline After treatment & $76 \%$ & $82 \%$ & $55,7 \%$ & $70 \%$ \\
\hline
\end{tabular}

\section{Discussion}

Because skin and psyche share embryonic origins, various psychological factors, including emotional trauma and stressful life events, may affect both onset and progression of some skin conditions (Papadopoulous et al., 1998) Results of this study revealed the assessment of patients with chronic psoriasis conditions that affect their interpretation of deferent life aspects, almost all studded sample were single about $71.89 \%$ that is because their age were between 18-62 years and most of patient was young beside that about $60 \%$ of the studded sample were between low and very low social class. So young patient of low social class with chronic disease unable to get proper treatment feel lack of control which is one of the most stressful aspects in psoriasis patients (Rapp et al 1998). Many patients experience social and psychological difficulties created by their environment (Seng and Nee 1997).Patients may feel humiliated when they need to expose their bodies during swimming, intimate relationships, using public showers, or living in conditions that do not provide appropriate privacy (Ginsburg and link1993).Many of the patients suffering from psoriasis often feel the need to hide their disease, thus severely affecting their self confidence (Wiss et al., 2002)

So these results showed that $59.5 \%$ of the total sample is unsatisfied with their global functioning, while $44.4 \%$ are satisfied. Which are compatible with results of different studies like (Demerdash et al., 2008) which was a study done on chronic patients with psychiatric disorders as regard their quality of life using Lehman Quality of
Life interview that results represented the effect of chronicity of diseases like psoriasis and psychiatric diseases.

As regard living situations, we found that $50.2 \%$ were unsatisfied, while $49.7 \%$ were satisfied. While their answers about daily work and activity was satisfied in $65.9 \%$ and unsatisfied for $34.1 \%$. Determinants of QoL in psoriasis patients

Various factors may be attributed to the lower QoL in psoriasis patients.

The chronic and recurring nature of this disease often brings about a feeling of hopelessness in terms of cure for the condition (Vardy et al., 2002)

People suffering from psoriasis feel that the general public and sometimes their own physicians fail to appreciate the negative impact of psoriasis on their life (Chio and Koo 2003and Krueger et al., 2001)

Psoriasis is also associated with limitations in daily activities, occupational, and sexual functioning(Gupta and Gupta 1997and Wahl et al., 2002). Patients with psoriasis suffer comparable disability as other patients with chronic illnesses (McKenna et al., 2003). Patients are constantly concerned with the interference with future plans due to an unexpected outbreak of symptoms. This possibly intensifies due to their lack of control over the disease (Vardy et al., 2002).

All these factors may have major effect on the patients' QoL

Results showed that $57.4 \%$ of patients were unsatisfied with their family relations and $43.5 \%$ are satisfied. However, about their social relations they were $55.3 \%$ satisfied while $44.6 \%$ were unsatisfied with 
it. Psoriasis has strong impact on social life, with patients frequently complaining of social difficulties and friction with family members.

In the other hand, they were $52.3 \%$ satisfied with their finance while the other $48.2 \%$ were unsatisfied with it. As regard, work or school they were $66.4 \%$ satisfied and $33.5 \%$ unsatisfied. While they were $85.1 \%$ satisfied with low, safety, and $14.8 \%$ unsatisfied. The same for health $94.4 \%$ satisfied and $6.5 \%$ unsatisfied. Among other factors including patients' age, gender, income, duration of psoriasis, and number of physicians seen in last two years. Increasing psoriasis severity was significantly associated with seeking care from multiple physicians (Jowett and Main 1985).

Psoriasis patients frequently feel ashamed and embarrassed about their condition and considered this to be the worst aspect of their disease (Fortune et al., 1997).High levels of stress in this population may often result from other people reacting to their disease or anticipation of the same (Fortune et al., 1997). In one qualitative study carried out to assess the determinants of QoL in the US population with psoriasis, body surface area showed the strongest association with affection in QoL . While measures of body surface area affected by psoriasis are commonly used in clinical trials to assess severity of the disease, there is a movement which argues that QoL standard would be a better method of determining the severity of psoriasis (Krueger et al., 2001 ). In the clinic setting, treatment judgments may be largely guided by QoL issues.

Quantification of the impact of psoriasis on the QOL, along with clinical severity assessment, as has been demonstrated in various studies, could provide a measure of the clinical efficacy of the dermatological therapies; since an important concept of a favorable treatment outcome in psoriasis is the improvement in the overall psychosocial morbidity associated with the disease(Kriby et al.,2001) Surprisingly, very few studies have looked into the psychological aspects of this chronic disfiguring disease. Thus the aims of our study were to assess the clinical severity, the physical and psychosocial disability and to analyze their interrelationship in psoriasis patients. We noticed that female with Psoriasis much complaining than male which is a women character.

Assessment of quality of life before and after treatment with different treatment modalities showed that group of patients with topical therapy did not experience improving their quality of life which is due to that topical therapy necessitates that patients apply multiple creams and ointment at various times of the day which can be second driver of the patients distress. Additionally, each of the topicals has its own adverse effects in addition to being expensive and time consuming. Topical steroids can thin the skin leading to easy bruisity and the development of stretch marks. Despite its remittive capability, patients find light therapy to be a constant life disruption because of the requirement visit a dermatologist's office almost daily. Additionally, there is evidence that longterm exposure to the ultraviolet prolonged treatment courses and fair (type I-II) skin increase risk of cancer (Krueger et al., 2001).Gupta et al., 2002 in their study of 127 psoriasis patients found that 9.7\% of patients reported their wish to dead, and $5.5 \%$ reported active suicidal ideation at the time of the study these studies have highlighted the need for psychosocial strategies in treating patients with psoriasis and help them to improve their QOL.

Conclusions Psoriasis is a disease with profound impact on the psychological and social aspect of the patient, particularly because of its visibility.Systemic therapy of psoriasis could improve their quality of life. Thus assessment by a health professional of the extent of apparent disease in terms of the clinical severity alone may not suffice, and a more holistic approach to the quality of life is mandatory.

\section{References:}

Choi J, Koo JY. Quality of life issues in psoriasis. J Am Acad Dermatol. 49:S57-S61; 2003.

De Arruda LH, De Moraes AP. The impact of 
psoriasis on quality of life. $\mathrm{Br} \mathrm{J}$ Dermatol. 144:33-36. 2001.

Demerdash A, El shafie. T, Ismail. R:Quality of life of psychiatric patients. Current Psychiatry. 15(1):32-41; 2008.

Fahmy SI, Elsherbini AF: Determining simple parameters for social classification for health researches. The Bull. of The High Institute Of Public Health, X: 95-108; 1988.

Feldman SR, Fleischer AB, Jr, Reboussin DM. The economic impact of psoriasis increases with psoriasis severity. J Am Acad Dermatol. 37:564-569; 1997.

Finlay AY, Coles EC. The effect of severe psoriasis on the quality of life of 369 patients. Br J Dermatol. 132:236-244; 1995.

Fortune DG, Main CJ, O'Sullivan TM: Quality of life in patients with psoriasis: the contribution of clinical variables and psoriasisspecific stress. Br J Dermatol. 137:755-760 1997.

Fortune DG, Richards HL, Griffiths CE: Psychologic factors in psoriasis: consequences, mechanisms, and interventions. Dermatol Clin. 23:681-694; 2005.

Ginsburg IH, Link BG. Psychosocial consequences of rejection and stigma feelings in psoriasis patients. Int J Dermatol. 32:587591;1993

Gupta MA, Schork NJ, Gupa AK, et al :Suicidal ideation in psoriasis .Int J Dermatol.147:736-742; 2002.

Gupta MA, Gupta AK. Psoriasis and sex: a study of moderately to severely affected patients. Int J Dermatol. ;36:259-262; 1997.

Jowett S, Ryan T: Skin disease and handicap: an analysis of the impact of skin conditions. Soc Sci Med. 20:425-429; 1985.

Kirby B, Richards HL, Woo P: Physical and psychological measures are necessary to assess overall psoriasis severity. J Am Acad Dermatol;45:72-6; 2001.

Krueger G, Koo J, Lebwohl M. The impact of psoriasis on quality of life: results of a 1998 National Psoriasis Foundation patientmembership survey. Arch Dermatol. 137:280284; 2001.

McKenna SP, Cook SA, Whalley D: Development of the PSORIQoL, a psoriasisspecific measure of quality of life designed for use in clinical practice and trials. $\mathrm{Br} \mathrm{J}$ Dermatol. 149:323-331; 2003.

Papadopoulous L, Bor R, Legg C: Impact of life events on the omset of vitiligo in adults. Clin Exp. Dermatology. 23;243; 1998.

Prins M, Krabbe F M,Swinkels $O$ G: The Effect of Treatment on Quality of life in Psoriasis Patients. Acta Derm Venereol. 85:304-310; 2005.

Rapp SR, Feldman SR, Exum ML. Psoriasis causes as much disability as other major medical diseases. J Am Acad Dermatol. 41:401-407; 1999.

Sajatovic M, Ramirez LF: Rating Scale in mental health. Lexi Comp INC Hudson, $2^{\text {nd }}$ ed. p 128, 256; 2003.

Seng KT, Nee ST. Group therapy: a useful and supportive treatment for psoriasis patients. Int J Dermatol. ;36:110-112; 1997.

Traver T, Duckmanton RA, Chiu E: A study of Quality of Life of the severely mentally ill. Int J Soc Psych. 44(2): 79-91; 1998.

Vardy D, Besser A, Amir M. Experiences of stigmatization play a role in mediating the impact of disease severity on quality of life in psoriasis patients. Br J Dermatol. 147:736742; 2002.

Wahl AK, Gjengedal E, Hanestad BR. The bodily suffering of living with severe psoriasis: in -depth interviews with 22 hospitalized patients with psoriasis patients. Qual Health Res. ;12:250-261; 2002.

Weiss SC, Kimball AB, Liewehr DJ: Quantifying the harmful effects of psoriasis on health-related quality of life. J Am Acad Dermatol, 4:512-518; 2002. 


\section{قياس معدل جودة الحياة فى مرضى الصدفية}

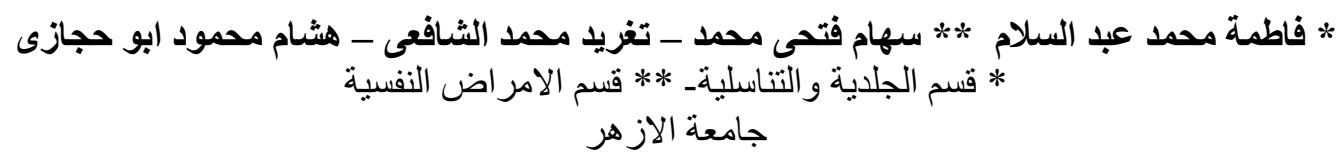

يشارك الجلد والنفس فى نفس المصدر التكوينى وتؤثر العو امل النفسية المختلفة مثل الصدمات النفسية

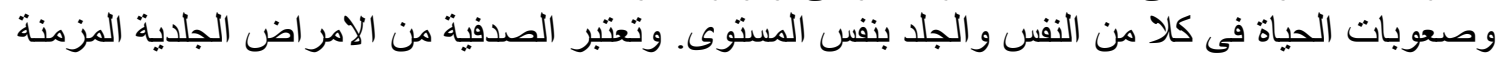

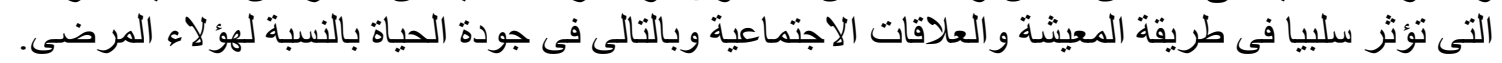
وقد ارتبط مرضى الصدفية بمرض الإكتئاب و الرغبات الإنياعة الانتحارية.

\section{طريقة البحث}

تضمنت هذه الدراسة خمسين مريضا مصابين بمرض الصدفية من الجنسين وتتراوح اعمار هم

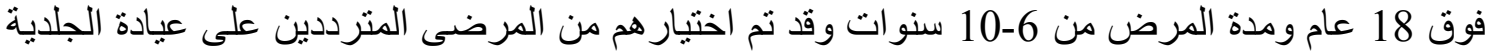
بمستشفى الزهر اء الجامعى. وقد تم تشخيصهم إكلينيكيا باستخدام معدل المساحة و الثدة (PASI). وتم اجر اء اختبار معدل جودة الحياة عن طريق استخدام مقياس ليمان لقياس جودة الحياة كما تم تقسيمهم الى ثناث انو أواع مختلفة.

علاج موضعى بمر اهم الكورنيزون و السالسيلك وعلاج ضونئي باستخدام (NB-UVB) و وعلاج

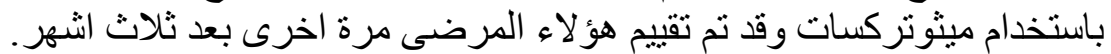

النتائج

وكانت النتائج كالاتى:- 57.4\% من المرضى كانو غير راضيين بالنسبة للعلاقات العائلية فى

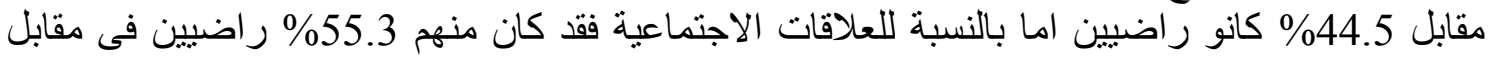

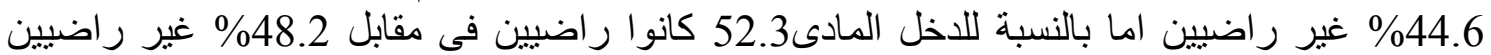

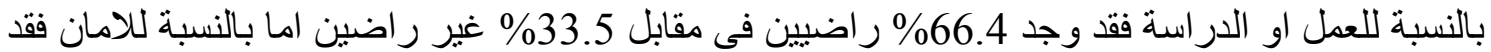

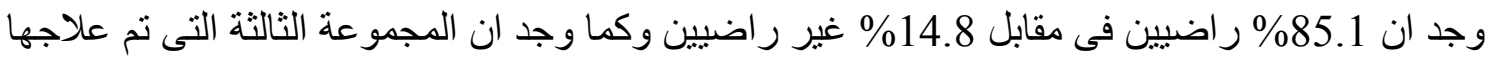

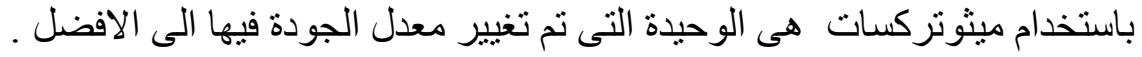

الملخص

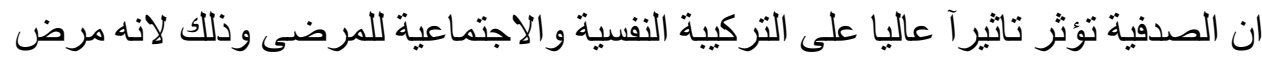

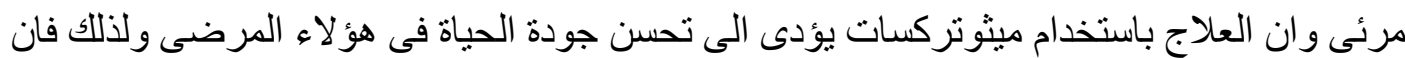

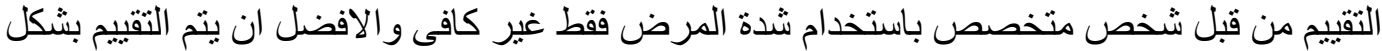
متكامل عن طريق استخدام جودة الحياة. 